$\underline{\text { Research article }}$

\title{
Antibacterial and anti-candida activity of chlorhexidine gluconate, Triphala and Munamal pothu (bark of Mimusops elengi)
}

\author{
GK Wijesinghe ${ }^{1}$, PDTA Jayarathna ${ }^{1}$, TDCP Gunasekara ${ }^{1}$, \\ N Fernando ${ }^{1}$, N Kottegoda ${ }^{2,3}$, MM Weerasekera ${ }^{1}$ \\ Sri Lankan Journal of Infectious Diseases 2018Vol.8(1):25-31 \\ DOI: http://dx.doi.org/10.4038/sljid.v8i1.8166
}

\begin{abstract}
Introduction and Objective: Chlorhexidine is used as an oral mouthwash to reduce oral colonization related to dental disease. Triphala (An ayurvedic preparation from the dried fruits of Emblica officinalis, Terminalia bellirica and Terminalia chebula) and Mimusops elengi(Munamal) are used as mouthwashes in Ayurvedic medicine and are known to have antimicrobial activity.

This study was aimed to determine the effect of $0.2 \%$ Chlorhexidine gluconate, Triphala and Mimusops elengi (Munamal) on Candida species and three common bacterial pathogens.

Methods: The effect of $0.2 \%$ chlorhexidine gluconate, Triphala and Mimusops elengi (Munamal) aqueous extracts against Candida spp., Staphylococcus aureus, and methicillin resistant Staphylococcus aureus (MRSA), Staphylococcus epidermidis, Escherichia coli and Pseudomonas aeruginosa were determined using an agar well diffusion method. Minimum inhibitory concentration (MIC) of Triphala and Munamal aqueous extracts for the microorganisms were determined using broth micro dilution method with alamar blue modification.

Results: $0.2 \%$ Chlorhexidine gluconate showed a zone of inhibition for all test microbial strains. Triphala demonstrated activity against all tested microbial species except Candida glabrata, Candida dubliniensis and Escherichia coli. Munamal Pothu demonstrated activity against Staphylococcus aureus and MRSA only. Chlorhexidine gluconate inhibited the growth of Candida (C. albicans and C. tropicalis) at 1/512 dilution ( $\mathrm{MIC}=0.004 \mathrm{mg} / \mathrm{ml}$ for both organisms). The MIC of Triphala for C. albicans and C. tropicalis was $32.5 \mathrm{mg} / \mathrm{ml}$. Anti-candida activity of Chlorhexidine gluconate was achieved at very low concentrations.
\end{abstract}

\footnotetext{
${ }^{I}$ Department of Microbiology, Faculty of Medical Sciences, University of Sri Jayewardenepura, Gangodawila, Nugegoda, Sri Lanka

${ }^{2}$ Department of Chemistry, Faculty of Applied Sciences, University of Sri Jayewardenepura, Gangodawila, Nugegoda, Sri Lanka

${ }^{3}$ Sri Lanka Institute of Nanotechnology (SLINTEC), Pitipana, Homagama, Sri Lanka

Address for correspondence: Dr. Manjula M. Weerasekera, Department of Microbiology, Faculty of Medical Sciences, University of Sri Jayewardenepura, Gangodawila, Nugegoda, Sri Lanka. Telephone: +094714432870

Email: mmweera@sjp.ac.lk; mmweera@yahoo.com @ ittps://orcid.org/0000-0002-8194-2205
}

Received 4 February 2018 and revised version accepted 7 May 2018 
Conclusions: Triphala as a potential oral mouthwash agent with activity against $C$. albicans and $C$. tropicalis requires further investigation.

Key words: Candida, Chlorhexidine, Triphala, Mimusops elengi (Munamal)

\section{Introduction}

Candida species, Pseudomonas species, Staphylococcus aureus and Escherichia coli are common microorganisms associated with serious superficial and systemic infections in man. ${ }^{1,2} S$. aureus is a major pathogen that causes a diverse range of infectious diseases. ${ }^{2} P$. aeruginosa is most commonly associated with chronic wound infections, ear infections and lung infections in patients with cystic fibrosis. ${ }^{3}$ These three pathogens cause community as well as hospital acquired infections while the ability of Pseudomonas spp. to form biofilms contribute to their success as a pathogen. ${ }^{4,5,6} \mathrm{MRSA}$ is a major cause of nosocomial infections. ${ }^{7}$ Available data show that MRSA accounts on average $57 \%$ of $S$. aureus isolates causing nosocomial infection in intensive care units (ICUs). ${ }^{7}$

Fungal species, mainly yeasts and Aspergillus species, are commonly associated with patients with diabetes mellitus. ${ }^{8}$ C. albicans accounts for $>90 \%$ of oral and systemic candida infections followed by C. tropicalis, C. parapsilosis, C. glabrata and C. krusei. ${ }^{9,10}$

Ayurvedic rasayana consisting of Amulaki/Nelli (Emblica officinalis), Bibhitaki/Bulu(Terminalia bellirica) and Halituki/Aralu (Terminalia chebula) commonly known as "Triphala" is effectively used in Ayurveda. ${ }^{11,12}$ Mimusops elengi(Munamal) ${ }^{13}$ is a plant known to have antimicrobial activity which is also used in ayurvedic medicine. In our study we investigated the effect of these ayurvedic preparations Triphala and Munamal and chlorhexidine on planktonic microorganisms in - vitro.

\section{Methods}

\section{Test strains and culture conditions}

Five Candida type strains, (C. albicans: ATCC10231; C. tropicalis: ATCC13803; C. parapsilosis: ATCC22019; C. glabrata: ATCC90030: C. dubliniensis: MYA 580), three Gram positive cocci $(S$. aureus: ATCC25923; S. epidermidis: ATCC14990; MRSA: a clinical isolate), and two Gram negative bacilli (E. coli: ATCC25922; P. aeruginosa: ATCC27853) were used for this study. Stock cultures of Candida species were maintained on Sabouraud Dextrose Agar (SDA, Sigma-Aldrich, USA) slants and were subcultured onto SDA plates and incubated at $35{ }^{\circ} \mathrm{C}$ for 24 hours. Other stock cultures were maintained on nutrient agar (NA)(Sigma-Aldrich, USA) slants and were subcultured onto NA plates and incubated at $35^{\circ} \mathrm{C}$ for 24 hours in order to obtain 24 hours fresh culture isolates.

\section{Preparation of herbal antifungal agents:}

Dried fruits of Terminalia chebula (aralu), Terminalia bellirica(bulu), Phyllanthus emblica(nelli), and dried bark of Mimusops elengi (Munamal pothu) were purchased from local vendors and identified and authenticated by the Botany Division, Bandaranayake Memorial Ayurvedic Research Institute, Sri Lanka. 
Preparation of Triphala: The dried plant materials were washed with running tap water and air dried for 48 hours. Each dried fruit (20.0 g) was measured. The mixture of three dried fruits was boiled by addition of 6 cups $(1440 \mathrm{ml})$ of distilled water, until the final volume of the extract was $240 \mathrm{ml}$, following the standard Ayurvedic protocol.

Preparation of Mimusops elengi extract: Dried Mimusops elengi bark (60.0 g) was used to prepare the aqueous extract using the same protocol.

An aliquot of prepared herbal aqueous extracts was freeze dried to determine the concentrations of working solutions. ${ }^{14}$ The prepared decoctions were filtered and stored at $4{ }^{\circ} \mathrm{C}$ up to two weeks until use. Chlorhexidine gluconate (Sigma Aldrich, USA) (0.2\%) was used as a control.

\section{Determination of the effect on planktonic cells}

Inhibitory activity of $0.2 \%$ Chlorhexidine gluconate and the two herbal plant extracts (Triphala and Mimusops elengi extract) on planktonic test organisms were determined using an agar well diffusion method as described by Magaldi, with few modifications. ${ }^{15}$ Standard suspensions (0.5 MacFarland) of test organisms were prepared in sterile normal saline and inoculated on Mueller-Hinton agar (MHA) separately to obtain a confluent growth. Five wells of $6 \mathrm{~mm}$ diameter each were prepared in each agar plate and the bottoms of the prepared wells sealed with $50 \mu \mathrm{l}$ of sterile MHA. $200 \mu \mathrm{l}$ of working solutions of $0.2 \%$ chlorhexidine gluconate, aqueous extracts of Triphala and Mimusops elengi were added into the wells separately with sterile distilled water as a negative control. $1.25 \mathrm{mg} / \mathrm{ml}$ Fluconazole (SigmaAldrich, USA) was used as positive control for Candida. $30 \mathrm{mg} / \mathrm{l}$ gentamicin solution was used as positive control for Gram negative test organisms and $30 \mathrm{mg} / \mathrm{l}$ vancomycin for Gram positive cocci tested. The diameter of the zone of inhibition was measured after overnight incubation of the agar plates at $37{ }^{\circ} \mathrm{C}$.

\section{Minimum inhibitory concentration (MIC)}

Minimum inhibitory concentration (MIC) of Candida was determined using the CLSI M-27A broth microdilution method with alamar blue modification. Suspensions of C. albicans and C. tropicalis $\left(1 \times 10^{6}\right.$ cells/ml) were prepared in sterile RPMI 1640 using 48-hour fresh Candida cultures.

The final concentration of Triphala extract was $65 \mathrm{mg} / \mathrm{ml}$ and Mimusops elengi extract12 mg/ml.

Serial two-fold dilutions $(1 / 2,1 / 4,1 / 8,1 / 16,1 / 32$ and 1/64) of antifungal agents were prepared using sterile distilled water. Prepared Candida suspensions $(100 \mu 1)$ were inoculated in triplicate to a sterile 96 well polystyrene microtiter plate and $100 \mu \mathrm{l}$ of each dilution of antifungal agent was added to each well. A $100 \mu \mathrm{l}$ of $0.02 \%$ Alamar blue stain was added to each well as an indicator. Plates were covered with a lid and sealed with parafilm and MIC was read after incubating the plate at $37^{\circ} \mathrm{C}$ for 48 hours. Any zone of inhibition (ZOI) in the agar well diffusion assay was considered as evidence of activity of the relevant ayurvedic preparation against each test organism. All tests were performed in triplicate.

\section{Results}

\section{Activity of chlorhexidine gluconate and two ayurvedic preparations}

The results of activity of working solutions of $0.2 \%$ Chlorhexidine gluconate, Triphala and Mimusops elengi aqueous extracts against test organisms are presented in Table 1. 
Chlorhexidine gluconate $(0.2 \mathrm{mg} / \mathrm{ml})$ showed a zone of inhibition for all ten test microbial strains. Among all Candida strains, Triphala demonstrated zones of inhibition only against $C$. albicans, $C$. tropicalis and

Table I: ZOI exhibited by $0.2 \%$ chlorhexidine gluconate, Triphala and Mimusops elengi extract against planktonic test organisms.

\begin{tabular}{lccc}
\hline Organism & \multicolumn{3}{c}{ Zone of inhibition in millimetres* } \\
\cline { 2 - 4 } & $\begin{array}{c}\text { Chlorhexidine } \\
\text { gluconate }(0.2 \mathrm{w} / \mathrm{v})\end{array}$ & $\begin{array}{c}\text { Triphala } \\
(65 \mathrm{mg} / \mathrm{ml})\end{array}$ & $\begin{array}{c}\text { Mimusopselengi } \\
(12 \mathrm{mg} / \mathrm{ml})\end{array}$ \\
\hline C. albicans & $22 \pm 1.25$ & $16 \pm 1.43$ & No ZOI \\
C. tropicalis & $20 \pm 2.20$ & $09 \pm 1.12$ & No ZOI \\
C. parapsilosis & $28 \pm 1.00$ & $18 \pm 1.50$ & No ZOI \\
C. glabrata & $24 \pm 1.00$ & No ZOI & No ZOI \\
C. dubliniensis & $25 \pm 2.25$ & No ZOI & No ZOI \\
S. aureus & $23 \pm 1.50$ & $22 \pm 1.00$ & $13 \pm 1.50$ \\
S. epidermidis & $28 \pm 1.00$ & $20 \pm 2.50$ & No ZOI \\
MRSA & $17 \pm 1.25$ & $17 \pm 1.00$ & $13 \pm 2.00$ \\
E. coli & $18 \pm 2.00$ & No ZOI & No ZOI \\
P. aeruginosa & $20 \pm 1.50$ & $17 \pm 1.00$ & No ZOI \\
*All experiments were done in triplicates. Data are mean \pm standard deviation of \\
three individual experiments
\end{tabular}

C. parapsilosis.

Triphala showed a ZOI against all tested Gram positive cocci and $P$. aeruginosa but not against E. coli.

Munamal pothu extract demonstrated activity only against $S$. aureus and MRSA.

MIC of the 3 test products against planktonic $C$. albicans and $C$. tropicalis

Table 2: MIC of the 3 test products

\begin{tabular}{lcc}
\hline Organism & $\begin{array}{c}\text { Product } \\
\text { tested }\end{array}$ & $\begin{array}{c}\text { MIC } \\
(\mathbf{m g} / \mathbf{m l})\end{array}$ \\
\hline C. albicans & $\begin{array}{c}\text { Chlorhexidine } \\
\text { gluconate } \\
\text { Triphala }\end{array}$ & 0.004 \\
& $\begin{array}{l}\text { Mimusops } \\
\text { C. tropicalis }\end{array}$ & - \\
& $\begin{array}{c}\text { elengi } \text { extract } \\
\text { Chlorhexidine } \\
\text { gluconate } \\
\text { Triphala }\end{array}$ & 0.004 \\
& $\begin{array}{l}\text { Mimusops } \\
\text { elengi } \text { extract }\end{array}$ & - \\
\hline *Three individual tests were performed in triplicate
\end{tabular}

As shown in Table 2, Chlorhexidine gluconate exhibited a MIC of $0.004 \mathrm{mg} / \mathrm{ml}$ for both planktonic Candida species. The MIC of Triphala for both Candida species was $32.5 \mathrm{mg} / \mathrm{ml}$. Mimusops elengi extracts did not exhibit any activity against these 2 species of candida. 


\section{Discussion}

Chlorhexidine gluconate $(0.2 \%)$, is a recommended, commercially available mouth rinse with reported activity against oral bacteria. ${ }^{16}$ In the present study also it showed an activity against free living planktonic cells which indicated its effectiveness in preventing microbial colonization and viability. However long term use of this antiseptic as an oral rinse has side effects, including staining of teeth, alteration of taste sensation and development of antimicrobial resistance. ${ }^{17}$ The use of alternative herbal extracts may help overcome these side effects. Mimusops elengi is known to have antimicrobial activity. ${ }^{13}$ It is also used for treating or controlling oral complications such as dental caries and gum bleeding. However, according to the present study this extract had no inhibitory effect against Candida or other bacterial species except $S$. aureus and MRSA.

Triphala is a common ayurvedic preparation used for a broad range of oral and non-oral infections. It is reported to have anti-inflammatory, antioxidant, and antimicrobial activity against a wide spectrum of microorganisms including bacteria, yeasts and dermatophytes. ${ }^{18,19,11}$ The active phytochemicals contributing to antimicrobial activity are tannic acid, chebulic acid, and flavonoids. Its antimicrobial activity against $C$. albicans and dermatophytes have been reported using the agar well diffusion assay. ${ }^{18}$ In this in-vitro study Triphala was found to show activity against $C$. albicans, $C$. tropicalis, $C$. parapsilosis, S. aureus, MRSA, S. epidermidis, and P. aeruginosa planktonic cells. Antibiofilm activity of Triphala has been reported which suggests its usefulness as a general antiseptic with low side effects. Triphala has been shown to be effective in reducing biofilms of both C. albicans and Enterococcus faecalis in one study. ${ }^{12}$

The MIC of Triphala for C. albicans and C. tropicalis was found to be $32.5 \mathrm{mg} / \mathrm{ml}$ in the current study. Further investigations are needed to determine the MIC of Triphala against the other Candida species. The current study demonstrates the antibacterial and anti-candida activity of Triphala. However, the role of Triphala against a wider spectrum of microorganisms, including oral colonizers would be useful in determining whether this ayurvedic product could be effectively used as an herbal mouth rinse to prevent oral pathogens including Candida species.

A limitation of this study is that only the aqueous extract of both Triphala and Mimusops elengi were tested for antimicrobial activity. It would be useful to test the ethanolic extracts of both and compare the antimicrobial activity of aqueous and ethanolic extracts.

\section{Conclusion}

The findings of this study further strengthen the effectiveness of $0.2 \%$ chlorhexidine gluconate as an antimicrobial agent. Triphala is a potential antimicrobial agent against $C$. albicans, $C$. tropicalis, $C$. parapsilosis, S. aureus, S. epidermidis, MRSA and P. aeruginosa. S. aureus and MRSA are sensitive to Munamal extract.

\section{Acknowledgement}


The authors would like to acknowledge Dr. P Ranasinghe, Industrial Technology Institute, Sri Lanka for providing facilities for Microtiter plate reader. Technical staff members of the Department of Microbiology Faculty of Medical Sciences, University of Sri Jayewardenepura, Sri Lanka are acknowledged for their technical support. The support of Bandaranayake Memorial Ayurvedic Research Institute, Navinna, Sri Lanka in authentication of plant materials is acknowledged.

Conflict of interests: There are no conflicts of interest

\section{References}

1. Chen T, YuWH, Izard J, et al. The Human Oral Microbiome Database: a web accessible resource for investigating oral microbe taxonomic and genomic information. Database 2010; Article ID baq013, doi: https://doi.org/10.1093/database/baq013.

2. $\quad$ Archer GL. Staphylococcus aureus:a well-armed pathogen. Clinical Infectious Diseases 1998; 26:11791181. doi: https://doi.org/10.1086/520289.

3. Klaus Kirketerp-Møller, Peter $\emptyset$ Jensen, Mustafa Fazli et al. Distribution, organization, and ecology of bacteria in chronic wounds. Journal of Clinical Microbiology 2008; 46:2717-2722 doi: https://doi:10.1128/JCM.00501-08.

4. Yoshikawa TT, Bradley SF. Staphylococcus aureus infections and antibiotic resistance in older adults. Clinical Infectious Diseases 2002; 34(2):211-216. doi: https://doi.org/10.1086/338150.

5. Flemming HC and Wingender J. The biofilm matrix. Nature Review Microbiology 2010; 8(9):623-633. doi: https://doi.org/10.1038/nrmicro2415.

6. Khan HA, Ahmad A, Mehboob R. Nosocomial infections and their control strategies. Asian Pacific Journal of Tropical Biomedicine 2015; 5(7):509-514. doi: https://doi.org/10.1016/j.apjtb.2015.05.001

7. National Nosocomial Infections Surveillance (NNIS) System Report; data summary from January 1992 through June 2002. American Journal of Infection Control 2003; 31:481-498. doi: https://doi:10.1016/j.ajic.2004.10.001.

8. Wijesuriya TM, Kottahachchi J, Gunasekara TD, et al. Aspergillus species: An emerging pathogen in onychomycosis among diabetics. Indian Journal Endocrinology and Metabolism 2015; 19(6):811-816. doi: https://doi:10.4103/2230-8210.167565.

9. Dilhari A, Weerasekera MM, Siriwardhana A et al. Candida infection in oral leukoplakia; an unperceived public health problem: Acta Odontologica Scandinavica. 2016;.74(7):565-569. doi: https://doi.org/10.1080/00016357.2016.1220018

10. Cannon RD, Holmes AR, Mason AB, Monk BC. Oral Candida: clearance, colonization, or candidiasis. Journal of Dental Research 1995; 74(5): 1152-1161. doi: https://doi:10.1177/00220345950740050301.

11. Biradar YS, Jagatap S, Khandelwal KR, Singhania SS. Exploring of antimicrobial activity of Triphala Mashi-an ayurvedic formulation. Evidence-Based Complementary and Alternative Medicine 2008; 5(1):107-113. doi: http://dx.doi.org/10.1093/ecam/nem002

12. Jyothi KN, Gopal A. Comparison of antimicrobial efficacy of $0.3 \%$ Propolis, $10 \%$ Neem, $10 \%$ Triphala and 5\% Sodium hypochlorite on Candida albicans and E. faecalis biofilm formed on root dentin: An in vitro study. Journal of Dental Sciences. 2016; 4(3):90-94 Nodoi

13. Deshpande RR, Ruikar A, Panvalkar PS, et al. Comparative evaluation of different concentration of Mimusops Elengi (L) extract as an antimicrobial against salivary microflora. Journal of Biomedical Science and Research. 2010; 2:51-4. No doi

14. Silva L, Borghetti F, de Lima EC. A simple procedure for the purification of active fractions in aqueous extracts of plants with allelopathic properties. Acta Botanica Brasilica. 2013; 27(1):50-53.

doi: https://dx.doi.org/10.1590/S0102-33062013000100007 
15. Magaldi S, Mata-Essayag S, Hartung de Capriles C, et al. Well diffusion for antifungal susceptibility testing. International Journal of Infectious Diseases 2004; 8(1):39-45.

doi: https://doi.org/10.1016/j.ijid.2003.03.002.

16. Talebi S, Sabokbar A, Riazipour M, Saffari M.Comparison of the in vitro effect of chemical and herbal mouthwashes on Candida albicans. Jundishapur Journal of Microbiology 2014; 7(12): e12563.

doi: https://doi.org/10.5812/jjm.12563

17. McCoy LC, Wehler CJ, Rich SE, et al. Adverse events associated with chlorhexidine use: Results from the department of veterans affairs dental diabetes study. Journal of American Dental Association 2008; 139:178-83 doi: https://doi.org/10.14219/jada.archive.2008.0134.

18. Gomes PLR, Hewageegana S, Kottahachchi J, et al. In vitro study to determine antimicrobial activity of selected ayurvedic preparations against bacteria and fungi causing superficial skin infections,Sri Lanka. Journal of InfectiousDiseases2013; 3(1):32-39. doi: http://dx.doi.org/10.4038/sljid.v3i1.4717.

19. Salam R, Sarker B K, HaqM R,Khokon JU. Antimicrobial activity of medicinal plant for oral health and hygiene. International Journal of Natural and Social Sciences 2015; 2 (1):1-15.No doi 